\title{
Appendix 2. Interview for the Diagnostic Criteria for Psychosomatic Research
}

Adapted by Mangelli L, Rafanelli C, Porcelli P, Fava GA from Rafanelli C, Roncuzzi R, Finos L, Tossani E, Tomba E, Mangelli L, Urbinati S, Pinelli G, Fava GA: Psychological assessment in cardiac rehabilitation. Psychother Psychosom 2003;72:343-349.

The interview concerns the past 6 or 12 months. It requires the knowledge of medical diagnoses and the chronology of the disorder's manifestations in the patient. The interviewer has to be familiar with the literature on DCPR. We recommend that the interview is made together with the psychiatric assessment.

\section{Health Anxiety}

A 1. Are you worried that you may have a serious illness? YES NO

2. If you are suffering from common symptoms (e.g. bleeding nose, a cold, headache, etc.) do you fear (e.g. become alarmed, consult your local doctor, request medical examinations, go to the hospital emergency department, consult a medical book, etc.) they may develop into a serious illness?

YES NO

(If No, skip to 'Disease Phobia')

B If the physician gives you an appropriate medical reassurance explaining that you don't have any illness and you are healthy, do you trust him? YES $\mathrm{NO}$

C Have you experienced these fears for the past 6 months? YES NO

Diagnosis: $A(1$ and/or 2$)=$ yes $+B=$ yes $+C=$ yes 


\section{Disease Phobia}

A Have you ever experienced severe anxiety, or a panic attack, as a result of being scared of having developed a bad disease?

YES $\square \quad$ NO

\section{(If No, skip to 'Thanatophobia')}

B Even though your doctor and the laboratory examinations have excluded any specific medical illness, are you afraid of suffering from a bad disease (e.g. AIDS, cancer)?

YES

NO

C Does your fear of a bad illness exceed 6 months?

YES

NO

Diagnosis: $A=$ yes $+B=$ yes $+C=$ yes

\section{Thanatophobia}

A Have you ever had the sense of impending death and/or conviction of dying soon, without being in a threatening situation or in real danger?

YES $\square \quad N O$

\section{(If No, skip to 'Illness Denial')}

B Are you afraid of news that reminds you of death (e.g. funerals, obituary notices)?

YES

C Do you avoid any situation that reminds you of death (changing the TV channel, interrupting a conversation if it concerns dead people, disasters or accidents)?

YES $\square \quad$ NO

Diagnosis: $A=$ yes $+B=$ yes $+C=$ yes 


\section{Illness Denial}

A 1 Have you ever neglected to bring to your physician's attention serious symptoms or ignored your physician's diagnosis and recommendations? YES

$$
\text { NO }
$$

2 If the physician tells you that you have a disorder and prescribes you drugs, a suitable diet or an appropriate physical activity, do you follow the medical advice?

$Y E S$

$$
\mathrm{NO}
$$

\section{(If $\mathrm{A} 1=$ no and $\mathrm{A} 2=$ yes, skip to 'Functional Somatic Symptoms Secondary to a Psychiatric Disorder')}

B Did the physician tell you that you have a medical disorder and provide a clear explanation of the medical situation and management to be followed?

YES

$$
\text { NO }
$$

Diagnosis: A (1 = yes and/or $2=$ no; or $1=$ yes and $/$ or $2=$ yes;

$$
\text { or } 1=\text { no and/or } 2=\text { no) }+B=\text { yes }
$$

\section{Functional Somatic Symptoms Secondary to a Psychiatric Disorder}

A Have you ever suffered from troublesome symptoms (e.g. palpitations, sweating, tremor, becoming flushed, gastrointestinal symptoms, dizziness, muscular pains, persistent tiredness) that interfered with your life causing repeated medical treatment?

YES

$$
\text { NO }
$$

\section{(If No, skip to 'Persistent Somatization')}

B Did the physician tell you that your physical symptoms are not due to a specific medical cause?
YES
NO

C The interviewer has to note if there is a psychiatric disorder YES

NO 
D If a psychiatric disorder exists, the interviewer must note the onset of the psychiatric disorder compared to the onset of the functional somatic disorder (e.g. psychiatric disorder occurred 6 months prior to functional somatic disorder; functional somatic disorder occurred 3 months prior to the psychiatric disorder)

YES

NO

NOTE: Yes = the functional somatic symptoms did not precede the onset of the psychiatric disorder

Diagnosis: $A=$ yes $+B=$ yes $+C=$ yes

(compare the onset of both the disorders)

\section{Persistent Somatization}

A Have you ever suffered for more than 6 months from one of the disorders I'm going to list to you and, as a consequence of them, have you sought medical treatment, or has your quality of life become worse?

- muscular pain and tingling

- persistent tiredness

- stomach pain with burning or bloating, or slow digestion

- constipation or diarrhea

- palpitations

- breathing difficulties

- other

YES

NO

\section{(If No, skip to 'Conversion Symptoms')}

B Is there a specific medical cause behind these disorders? YES $\mathrm{NO}$

C 1 If you took medication for these disorders, did they give you troublesome side effects?

YES $\square \quad$ NO

2 Did you feel worse? YES

3 Besides your main disorder, have you experienced any other problems?

$Y E S$

NO

Diagnosis: $\mathrm{A}=$ yes $+\mathrm{B}=$ no $+\mathrm{C}(1$ and/or 2 and/or 3$)=$ yes 


\section{Conversion Symptoms}

A Have you ever suffered from one of the following physical disorders (balance problems, localized paralysis or weakness, loss of voice, eating difficulty, double vision or loss of sight)?

$Y E S$

NO

\section{(If No, skip to 'Anniversary Reaction')}

B Did the physician find a specific medical cause or a specific factor to explain your symptoms?

YES

NO

C 1 Did any specific event occur before the manifestation of these symptoms? YES

NO

If yes, do you believe the symptoms are linked to this event?

YES

NO

2 Have you ever had the same symptoms in the past?

YES

NO

Or have you observed the same symptoms in someone else close to you?

YES

NO

3 The interviewer has to assess if the patient shows ambivalence as to the symptom

YES

NO

4 The interviewer has to assess the characteristics of histrionic personality

YES

NO

Diagnosis: $A=$ yes $+B=$ no $+C$ (at least 2 of the 4 characteristics $)=$ yes

\section{Anniversary Reaction}

A If you have suffered from one or more of the symptoms I listed to you before (e.g. palpitations, sweating, tremor, becoming flushed, gastrointestinal symptoms, dizziness, muscular pains, persistent tiredness, balance problems, localized paralysis or weakness, loss of voice, eating difficulty, double vision or loss of sight), and the physician didn't find any specific medical cause, do you remember a specific time that preceded the occurrence of the symptoms?

YES

NO

(If No, skip to 'Type A Behavior') 
B 1 Do you remember if they occurred at the same time as an important date for you, or at the same age that a family member developed a lifethreatening illness?

YES

NO

If yes, do you believe the symptoms are linked to this event?

YES

NO

2 Have any of your family members had serious health problems or died at the same age as you are now?

YES

NO

Diagnosis: $\mathrm{A}=$ yes $+\mathrm{B}(1$ and/or 2$)=$ yes

\section{Type A Behavior}

A 1 Do you often stay at work after your normal shift to finish some activities subject to deadlines, where you feel particularly responsible?

YES

NO

2 Do you often have a strong sense of time urgency to finish activities (either at work or not) you have started?

$Y E S$

NO

3 Does the patient have a rapid and explosive speech, abrupt body movements, hand gestures, and tensing of facial muscles?

YES

NO

4 When you feel a strong sense of time urgency, do you become aggressive with the people around you?

YES $\square \quad N O$

5 Do you often feel irritable?

YES $\square \quad N O$

6 Are you inclined to walk, move, act, and gesticulate quite fast? YES

NO

7 Do you feel you have many ideas and thoughts at the same time? YES

$\mathrm{NO}$

8 Do you feel you are very ambitious at work, desiring for achievements and more recognition than other people?

YES

NO

9 Do you feel in competition with your colleagues?

\section{(If less than 5 = yes, skip to 'Type A Behavior')}

B Do you have physical symptoms, such as palpitations, sweating, muscular and stomach pains, intestinal disorders, and/or breathing fast? YES

NO

Diagnosis: $A$ (at least 5 characteristics $)=$ yes $+B=$ yes 


\section{Irritable Mood}

A 1 When you sometimes feel irritable (either brief or prolonged episodes, occasionally or persistent), do you need to make an increased effort to control your temper?

YES

NO

2 Or do you have uncontrollable verbal or behavioral outbursts (e.g. shout, slam the door, bang your fists on the table)?

YES $\square \quad N O$

(If No, skip to 'Demoralization')

B After that, do you still feel bad?
YES
NO

C When you are irritable, do you feel your heart beating fast and other symptoms coming on?

YES $\square \quad N O$

Diagnosis: A (1 and/or 2 and/or 3) $=$ yes $+\mathrm{B}=$ yes $+\mathrm{C}=$ yes

\section{Demoralization}

A 1 Do you feel you have failed to meet your expectations or those of other people (concerning your work, family, social and/or economic status)? YES $\square \quad N O$

2 Is there an urgent problem you feel unable to cope with?
YES
$\mathrm{NO}$

3 Do you experience feelings of helplessness, hopelessness, and/or giving up?

YES

NO

(If No, skip to 'Alexithymia')

B Does your state of feeling exceed a month?
YES
NO

C Did this feeling occur before the manifestation of a physical disorders or exacerbate it?

YES

NO

Diagnosis: A (1 and/or 2 and/or 3) $=$ yes $+\mathrm{B}=$ yes $+\mathrm{C}=$ yes 


\section{Alexithymia}

The interviewer should assess the overall content of the interview and nonverbal behavior, in addition to the following questions:

A 1 When you experience something good or bad, are you able to describe your emotions (delight, joy, worry, sadness, anger)?

YES

NO

2 When you experience either good or bad events, do you talk about what has happened and what you feel inside of you?

$$
\text { YES } \square \quad N O
$$

3 Do you often daydream and let your imagination run away?

$$
\text { YES } \square \quad N O
$$

4 Do your thoughts concern more often your internal emotions and feelings?

YES $\square \quad$ NO

5 When you experience a strong emotion, do you also feel physical reactions? (e.g. sick to stomach, etc.?)

$$
\text { YES } \square \quad N O
$$

6 Have you ever had occasional but violent outbursts of anger, crying, or joy, that are inappropriate either in relationship with what was happening or your usual behavior?
YES
NO

Diagnosis: $A 1=$ no; $A 2=$ no; $A 3=$ no; $A 4=$ no $; A 5=$ no A6 $=$ yes (at least 3 characteristics) 